\title{
MASSIVE IRRIGATION DURING ENDOSCOPIC UROLOGIC SURGERY NORMAL SALINE VERSUS DISTILLED WATER; A PROSPECTIVE RANDOMIZED TRIAL
}

\author{
Bahaa E. Ewees, Ahmed N. Elshaer, Rania Magdy and Mohamed Maher
}

\begin{abstract}
:
Department of Anesthesia \& Intensive Care and Pain Management. Faculty of Medicine - Ain Shams University .Corresponding :

Mohamed maher

Mobile: 01101112004

E mail:

dr.mody2605@gmail.com

Received: 5/6/2019

Accepted: 23/6/2019

Background: Benign prostatic hyperplasia is the most prevalent non-malignant prostate disease affecting over $50 \%$ of the aging male population. Transurethral prostate resection (TURP) is the standard reference (i.e. the most effective endoscopic surgical procedure for this disorder).

Aim of the study: To compare the effectiveness and safety of normal saline vs sterile distilled water in massive irrigation in urological endoscopic surgery (TURP) as regards electrolyte disturbance $\left(\mathrm{Na}^{+}\right.$level), serum creatinine and occurrence of TURP syndrome.

Patients and Methods: This study included fifty male patients with benign prostatic hyperplasia, aging 50-70 years old, admitted to operating room in Ain Shams University hospitals for TURP. The patients were divided into two equal groups, Group 1: underwent endoscopic urological surgery (TURP) with normal saline wash using bipolar resectoscope, Group 2: underwent endoscopic urological surgery (TURP) with distilled water wash using monopolar resectoscope.
\end{abstract}

Results: The current study showed significant decrease in serum $\mathrm{Na}^{+}$level in distilled water group than in normal saline group in both postoperative and $24 \mathrm{hr}$ later. Also, we found significant decrease in hemoglobin level at $24 \mathrm{hr}$ postoperative in distilled water group compared to saline group.

Conclusion: Our results demonstrate that normal saline wash during TURP causes less drop-in serum sodium and $\mathrm{Hb}$ level, less fluid overload, less incidence of TURP syndrome and decreased need for blood transfusion than using distilled water as irrigant. wash.

Key words: TURP, endoscopic urologic surgery, normal saline

\section{INTRODUCTION:}

Transurethral resection prostatectomy is considered the main line of therapy for symptomatic benign prostatic hyperplasia $(\mathrm{BPH})$, due to its well-documented long-term efficacy. The use of an irrigating fluid is needed to dilate the surgical field \& washout debris and blood. Serious complications can result from the systemic absorption of irrigating fluid. However, the optimal irrigation solution is still doubtful. Different irrigation solutions are used in various urological centers as there is still no agreement on which irrigation solution is best for irrigation $^{(1)}$.

Normal saline is a physiological solution that can be given intravenous with minimal side effects. Studies comparing use of normal saline with different irrigation fluids have 
shown advantages including less incidence of bleeding and hyponatremia ${ }^{(2)}$.

Sterile water is used because it is widely accessible and of low viscosity. The magnitude risk of TUR syndrome with sterile water is controversial, while many are convinced that TUR syndrome occurs in patients who receive sterile water as an irrigant more frequently than other solutions ${ }^{(3)}$.

\section{AIM OF THE STUDY:}

The aim of this study is tocompare the effectiveness and safety of normal saline vs sterile distilled water in massive irrigation in urological endoscopic surgery (TURP) as regards electrolyte disturbance $\left(\mathrm{Na}^{+}\right.$level), serum creatinine and occurrence of TURP syndrome.

\section{PATIENTS AND METHODS:}

This randomized prospective study has been carried out in Ain Shams University Hospitals between January 2018 till January 2019 after approval of Research Ethics Committee (REC) at Ain Shams University and written informed consent from all the patients.

Eligibility of patients for the study included male patients age of 50-70 years, ASA physical status I-II, with serum creatinine level $<1.6 \mathrm{mg} / \mathrm{dl}$ undergoing elective endoscopic urological surgery (TURP) under regional anesthesia, with an anticipated duration of about 1.5-3.0 hours and irrigation volume more than 20 liters.

\section{Exclusion criteria:}

Patients were excluded from the study if they had significant renal dysfunction (e.g., creatinine level $>1.6 \mathrm{mg} / \mathrm{dL}$ ), and/or severe hepatic dysfunction (e.g. Child-TurcottePugh Scoring System "3") or an allergy to any medication used during anesthesia.
Patients complying with all inclusion and exclusion criteria were randomly assigned to two equal groups 25 patients each

Group 1: underwent endoscopic urological surgery (TURP) with normal saline wash using bipolar resectoscope.

Group 2: underwent endoscopic urological surgery (TURP) with distilled water wash using monopolar resectoscope.

All irrigation fluids were warmed to avoid hypothermia and all patients had been operated by the same surgical team.

\section{Study procedure:}

History, clinical examination and routine investigations including complete blood count $(\mathrm{CBC})$, random blood sugar (RBS), liver function test (LFT), kidney function test (KFT), prothrombin time (PT) and partial thromboplastin time (PTT) were performed to all patients.

All patients after admission to preinduction area were checked for name, medical history, vital signs, fasting for at least 6 hours, exclusion criteria, and operative site.

An intravenous (IV) cannula inserted, Basic monitoring including ECG, pulse oximetry and non-invasive blood pressure applied to all patients and intravenous preload was given by using Ringer acetate $(10 \mathrm{ml} / \mathrm{kg})$.

Premedication with midazolam 1-2mg was given until patients were comfortable during procedure while maintaining a meaningful patient contact. The regional block was done in sitting position.

After sterilization of the back of the patient using bovidone iodine, and under complete aseptic precaution, local infiltration of $3 \mathrm{ml}$ lidocaine, $25 \mathrm{G}$ spinal needle was inserted in para-median approach followed by injection of hyperbaric 
bupivacaine $0.5 \% 3.5 \mathrm{ml}$ with $25 \mathrm{ug}$ fentanyl so the total volume was $4 \mathrm{ml}$.

After 5 minutes from injection of local anesthetic, the assessment of sensory block was done using pinprick test to be above T10.

The heart rate, systolic and diastolic blood pressure had been recorded every 3 min. Samples for arterial blood gas analysis and electrolyte estimation had been drawn before start of irrigation as baseline values. Body temperature had been monitored throughout the procedure.

At the end of the procedure, Electrolytes $\left(\mathrm{Na}^{+}\right.$and $\left.\mathrm{Cl}^{-}\right)$and arterial blood gases had been again measured in post-operative room. The total duration of surgery was documented from the start of using the endoscope till its removal. The volumes of total irrigation fluid used had been recorded.

Hemoglobin, serum creatinine and serum sodium level had been estimated after $24 \mathrm{~h}$ post-operatively. Number of blood units transfused, if any, had been also recorded.

In case of occurrence of TURP syndrome, the management was:

1- Hemostasis and ending the surgery as soon as possible.

2- O2 mask up-to intubation and ventilation as needed.

3- Symptomatic treatment of nausea, vomiting and agitation in mild cases.

4- Sampling of serum $\mathrm{Na}^{+}$level and correction of hyponatremia using hypertonic saline $3 \%$.
5- Transfer the patient to high dependency unit or the intensive care according to the severity.

\section{Primary end point:}

The primary end point was the incidence of occurrence of TURP syndrome in both groups.

\section{Shifting from one group to the other:}

If the incidence of TURP syndrome in one group was more than the recorded incidence worldwide, which is between $0.5 \%$ and $8 \%{ }^{(4)}$.

\section{Statistical analysis:}

Recorded data were analyzed using the statistical package for social sciences, version 20.0 (SPSS Inc., Chicago, Illinois, USA). Quantitative data were expressed as mean \pm standard deviation (SD). Qualitative data were expressed as frequency and percentage.

\section{The following tests were done:}

$>$ The confidence interval was set to $95 \%$ and the margin of error accepted was set to $5 \%$. So, the p-value was considered significant as the following:

Probability (P-value)

- P-value $\leq 0.05$ was considered significant.

- P-value $\leq 0.001$ was considered as highly significant.

- $\quad$ P-value $>0.05$ was considered insignificant. 
Bahaa E. Ewees, et al.,

\section{RESULTS:}

Table (1): Demographic data distribution.

\begin{tabular}{|c|c|c|c|}
\hline Demographic data & Group I: $(n=25)$ & Group II:(n=25) & p-value \\
\hline Age (years) (mean \pm SD) & $61.86 \pm 8.66$ & $60.83 \pm 7.52$ & 0.690 \\
\hline \multicolumn{4}{|l|}{ ASA (no., $\%)$} \\
\hline $\mathrm{I}$ & $9(36 \%)$ & $7(28 \%)$ & \multirow{2}{*}{0.762} \\
\hline II & $16(64 \%)$ & $18(72 \%)$ & \\
\hline $\begin{array}{l}\text { Duration of surgery (min) } \\
\quad(\text { mean } \pm \text { SD) }\end{array}$ & $124.75 \pm 17.47$ & $127.84 \pm 17.90$ & 0.584 \\
\hline
\end{tabular}

Table (2): Comparison of hemoglobin level between the 2 groups.

\begin{tabular}{|l|l|l|l|}
\hline \multicolumn{1}{|c|}{ Hemoglobin $(\mathrm{g} / \mathrm{dl})$} & Group I: $(n=25)$ & Group II:(n=25) & $\mathrm{p}$-value \\
\hline Pre-operative & $12.26 \pm 0.74$ & $12.35 \pm 0.74$ & 0.703 \\
\hline Post-operative & $11.99 \pm 0.72$ & $11.87 \pm 0.71$ & 0.599 \\
\hline 24 hr later & $11.71 \pm 0.70$ & $11.38 \pm 0.68$ & $0.013^{*}$ \\
\hline
\end{tabular}

p-value $>0.05 \mathrm{NS}$; ${ }^{*}$-value $<0.05 \mathrm{~S}$, data are presented as mean $\pm \mathrm{SD}$.

This table shows statistically significant decrease of hemoglobin level in group II compared to group I, $24 \mathrm{hr}$ postoperatively.

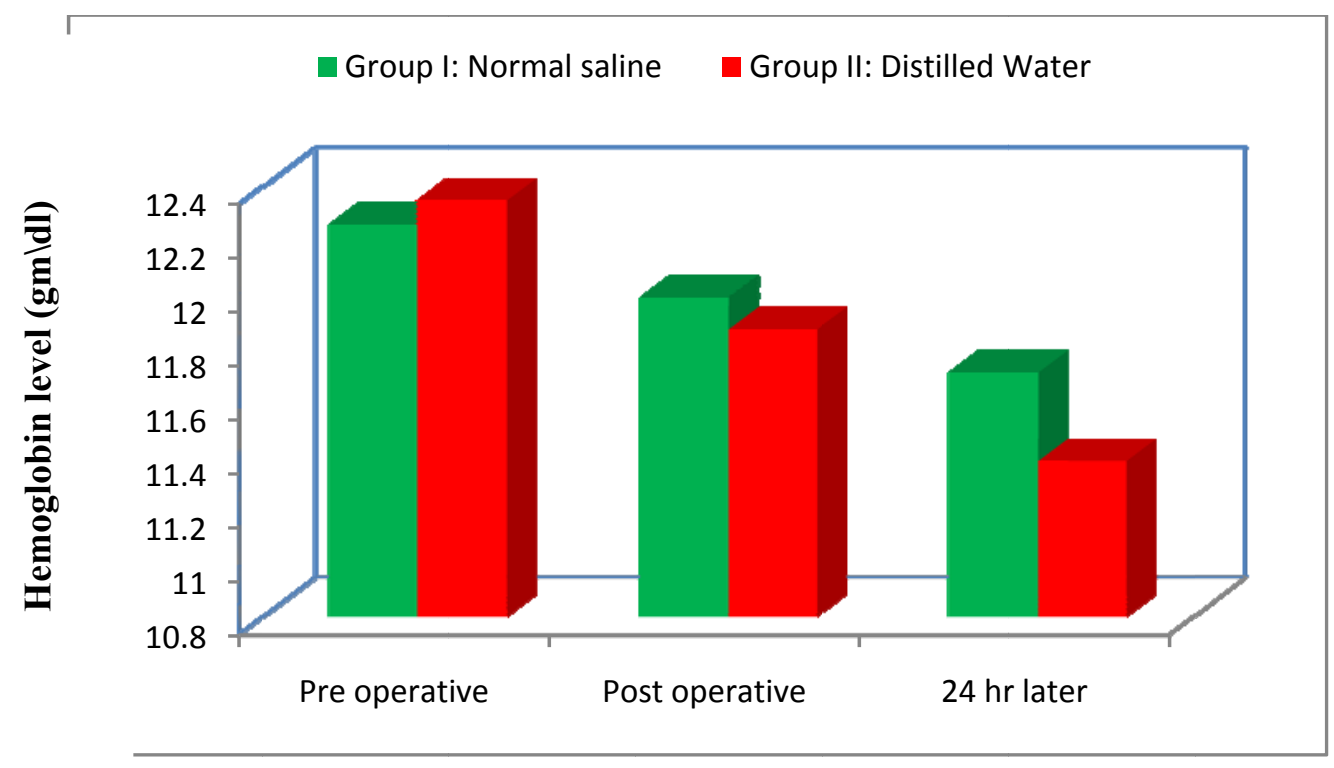

Fig. (1): Bar chart of hemoglobin level between the 2 groups.

Table (3): Comparison of serum sodium level between the 2 groups.

\begin{tabular}{|l|l|l|l|}
\hline Serum sodium level (mg\dl) & Group I: $(n=25)$ & Group II:(n=25) & -value \\
\hline Pre-operative & $139.63 \pm 5.57$ & $140.61 \pm 6.44$ & 0.572 \\
\hline Post-operative & $136.83 \pm 6.32$ & $131.18 \pm 10.32$ & $0.02^{*}$ \\
\hline 24 hr later & $132.73 \pm 5.53$ & $128.21 \pm 8.90$ & $0.036^{*}$ \\
\hline
\end{tabular}

p-value $>0.05 \mathrm{NS} ; \quad{ }^{*}$-value $<0.05 \mathrm{~S}, \quad$ data are presented as mean $\pm S D$.

This table shows statistically significant decrease of serum $\mathrm{Na}^{+}$level in group 2 compared to group 1 at post-operative and $24 \mathrm{hr}$ later. 


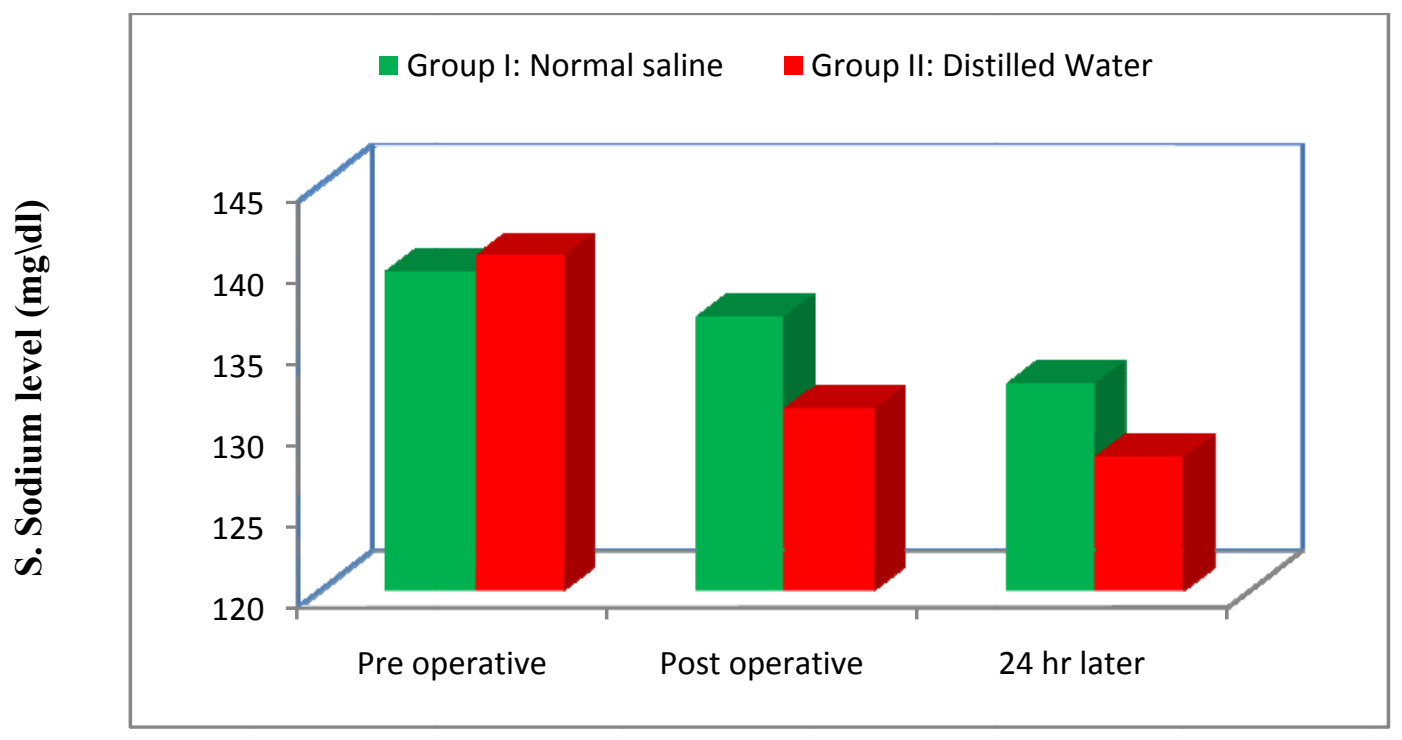

Fig. (2): Bar chart of serum sodium level between the 2 groups.

Table (4): Comparison of occurrence of TURP syndrome between the 2 groups.

\begin{tabular}{|l|l|l|l|}
\hline \multicolumn{1}{|c|}{ Occurrence of TURP syndrome } & Group I: $(\mathrm{n}=25)$ & Group II: $(\mathrm{n}=25)$ & $\mathrm{p}$-value \\
\hline Yes & $0(0 \%)$ & $1(4 \%)$ & 1.00 \\
\cline { 1 - 3 } No & $25(100 \%)$ & $24(96 \%)$ & \\
\hline \multicolumn{2}{|l|}{-value $>0.05 \mathrm{NS}, \quad$ data are presented as no. (\%). }
\end{tabular}

This table shows no statistically significant difference between groups regarding the occurrence of TURP syndrome.

\section{DISCUSSION:}

In this study, the two studied groups had no statistically significant differences in preoperative demographic data as age and ASA physical status. Duration of surgery was also statistically non-significant between both groups. The main finding in this study was significant decrease in $\mathrm{Na}^{+}$level in distilled water group than in normal saline group in both postoperative and $24 \mathrm{hr}$ later.

In concordance with our study, Ebeid et al., 2018 who compared standard monopolar versus bipolar saline in TURP on 100 male patients whom were allocated on 2 equal groups monopolar group used glycine and bipolar group used normal saline as irrigant and found that the decline in monopolar glycine group was more than the bipolar saline group. However, the result was statistically non-significant ${ }^{(5)}$.Also, Kulshreshtha et al., 2017 who performed a comparative study of 'sterile water' versus 'glycine (1.5\%)' as irrigation fluid in TURP on a total of 60 patients and found the serum sodium concentration was decreased significantly after TURP surgery in both the groups. Immediately after TURP, the decrease in serum sodium was significantly more in sterile water group as compared to glycine group $^{(6)}$.

On the other hand, Pasha et al., 2015, who studied postoperative complication with glycine and sterile distilled water after TURP which was conducted on a total of 170 adult male patients between $50-80$ years of age undergoing TURP, found that the difference between both the groups in postoperative serum sodium level being nonsignificant ${ }^{(7)}$. Also, Yousef et al. 2010 who compared between three types of irrigating fluids during transurethral resection in benign prostatic hyperplasia which were 
conducted on 360 male patients whom were divided on 3 groups one group used D5\% as irrigant, the second one used $1.5 \%$ glycine and the $3^{\text {rd }}$ group used $0.9 \%$ normal saline and found that insignificant decrease in the postoperative serum sodium was observed in glycine and glucose groups, while insignificant increase was observed in saline group $^{(3)}$. Also, Moharari et al., 2008 who studied sterile water as an irrigating fluid for transurethral resection of the prostate: anesthetical view of the records of 1600 Cases found that the decline in serum sodium level was statistically nonsignificant ${ }^{(8)}$.

In the current study, we had found statistically significant decrease in hemoglobin level at $24 \mathrm{hr}$ postoperative in distilled water group compared to saline group. However, we found that there was no statistically significant difference between groups regarding number of blood units transfused.

In concordance with our study was Treharne et al., 2018 who performed systematic review and meta-analysis on the economic value of the transurethral resection in saline system for treatment of benign prostatic hyperplasia in England and Wales found that the results of the meta-analysis showed a statistically significant reduction in blood transfusions with use of TURP in saline compared with monopolar TURP ${ }^{(\mathbf{9})}$.

In our study, there was only one case of TURP syndrome in sterile distilled water group versus no cases in normal saline group. Difference between the two groups was not statistically significant.

\section{Conclusion}

Our results demonstrate that normal saline wash during TURP causes less dropin serum sodium and $\mathrm{Hb}$ level, less fluid overload, less incidence of TURP syndrome and decreased need for blood transfusion than using distilled water as irrigant.
Based on our study, we recommend using normal saline as an irrigation fluid in endoscopic urologic surgery.

\section{REFERENCES:}

1. Hahn R. G. Fluid absorption in endoscopic surgery. Review article British Journal of Anesthesia; 2006,1:820

2. Starkman JS and Santucci RA. Comparison of bipolar transurethral resection of the prostate with standard transurethral prostatectomy: shorter stay, earlier catheter removal and fewer complications. $\mathrm{Br} J$ Urol Int; 2005, 95:69-71

3. Yousef AA, Suliman GA, Elashry OM et al. A randomized comparison between three types of irrigating fluids during transurethral resection in benign prostatic hyperplasia. BMC Anesthesiol.; 2006, 10:7.

4. Aziz W, Ather MH. Frequency of electrolyte derangement after transurethral resection of prostate: need for postoperative electrolyte monitoring. Advances in Urology; 2015, 1-5.

5. EbeidAI,KotbA,Rehan MR et al. Transurethral resection of prostate:A comparison of standerd monopolar versus bipolar saline resection Afr J Urol; 2018, 397.

6. Kulshreshtha K, Tambey R, Tirpude NG. A comparative study of sterile water' versus 'glycine $(1.5 \%)$ ' as irrigation fluid in transurethral resection of prostate. JMSCR;(5): 2016, 2145462.

7. Pasha TM, Khan MA, Jamal Y et al. Postoperative complication with glycine and sterile distilled water after TURP J Ayub Med Coll Abbottabad;2015, 27(1)

8. Moharari RS, Khajavi MR, Khademhosseini $\mathrm{P}$ et al. Sterile water as an 
irrigating fluid for transurethral resection of the prostate: anesthetical view of the records of 1600 cases. South Med J.; 2008, 101:373-5.

9. Treharne C, Crowe L, Booth D et al. Economic value of the transurethral resection in saline system for treatment of benign prostatic hyperplasia in England and Wales: Systematic Review, Meta-analysis, and cost consequence model. European Urology focus 4; $2018,270-9$.

\section{الغسيل المكثف اثناء جراحات المسالك البولية بالمنظار \\ محلول الملح في مقابل الماء المقطر، دراسة عشوائية احتمالية. \\ بهاء الاين عويس, أحمد نجاح الثاعر ,رانيا مجدي علي محمد ماهر عبد الفتاح عبد العزيز}

المقدمة: تضخم البروستاتا الحميد هو احد أكثر اضطر ابات البروستاتا الغير الخبيثة شيو عا ، حيث بصيب أكثر من

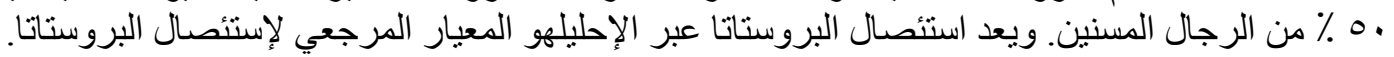

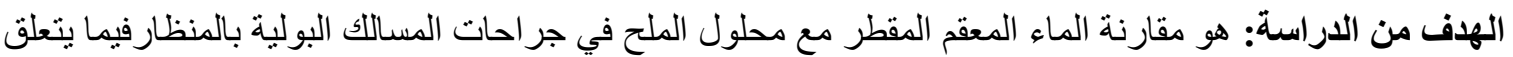

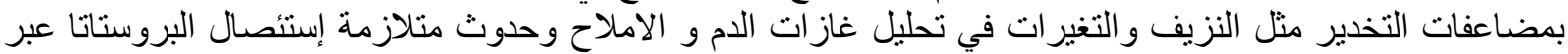

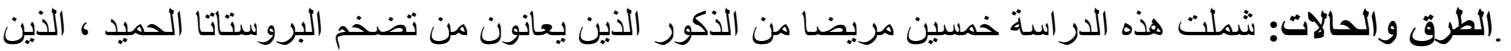

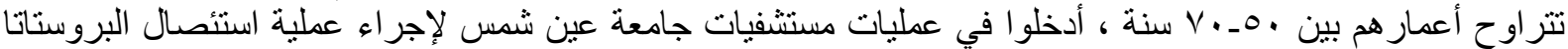

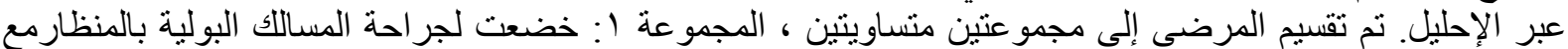

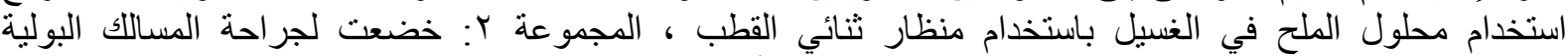
بالمنظارمع استخدام الماء المقطر في الغسيل باستخدام المنظار أحادي القطب.

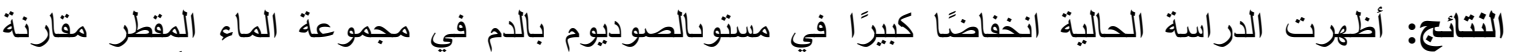

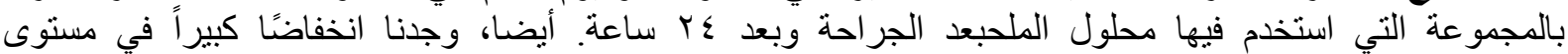

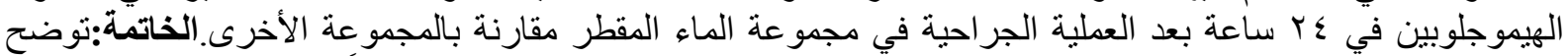

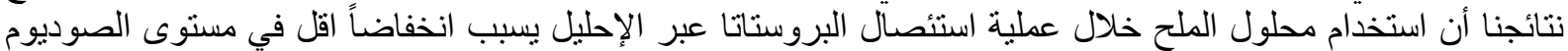

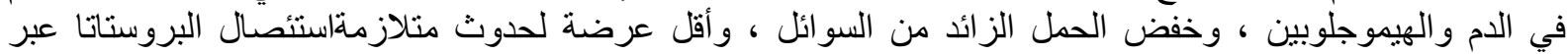
الإحليل وانخفاض الحاجة إلى نقل الدم من استخدام الماء المقطر. 